\title{
If You Want To Learn - Take on the Most Difficult Problem
}

And who better to learn from than the leaders themselves? The editors of Healthcare Quarterly asked four leaders in the healthcare business about their toughest assignments and the lessons they learned.

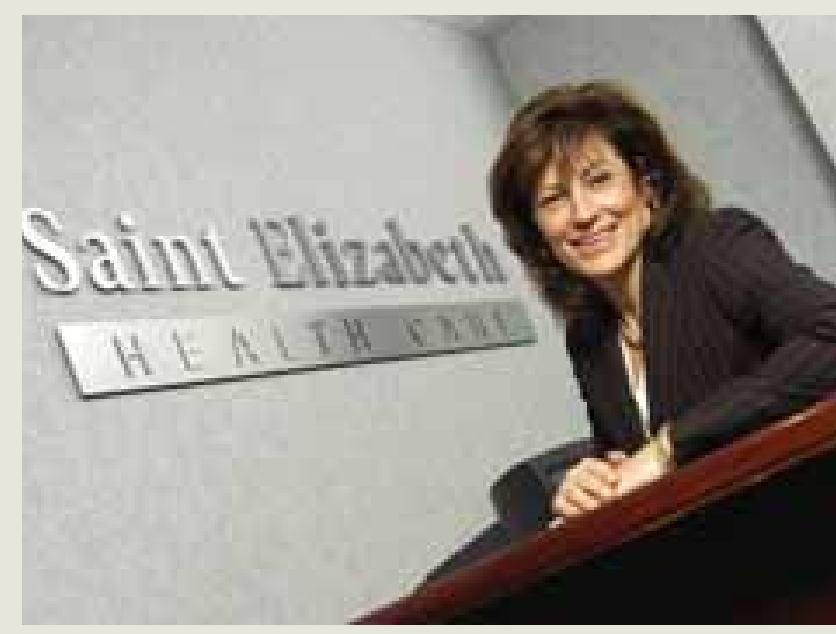

Shirlee Sharkey, BA, BScN, MHSc, CHE

Shirlee Sharkey is President and CEO of Saint Elizabeth Health Care. Under her 11-year leadership, Saint Elizabeth Health Care has demonstrated tremendous growth and diversification by expanding beyond direct client care and into the areas of consultation, knowledge exchange and technology solutions to support other health organizations.

Sharkey is a board member of the Canadian Society for Telehealth; Smart Systems for Health Agency; and the Change Foundation of the Ontario Hospital Association. She is cross-appointed as an assistant professor to the University of Toronto's Faculty of Nursing and the Faculty of Medicine, Department of Health Policy, Management and Evaluation.

My time at Saint Elizabeth Health Care has really been my most challenging, inspiring and fulfilling career assignment.

When I joined Saint Elizabeth Health Care, it was clear the organization had a strong record of innovation. One of my more interesting challenges as President and CEO was to develop greater focus and rigor in this area by ensuring that the culture and practice of innovation permeated throughout the organization. After reviewing the literature and looking to other industries for inspiration and wisdom, we signalled our commitment to innovation through the creation of an Idea Factory, thereby providing staff time and space to play, reflect, imagine, share, grow and celebrate.

To further integrate innovation into daily worklife, we created flexible processes to stimulate and encourage ideas to come forward from across the organization and to test, experiment and implement those that are valuable and viable. We call it Innovation Fever!

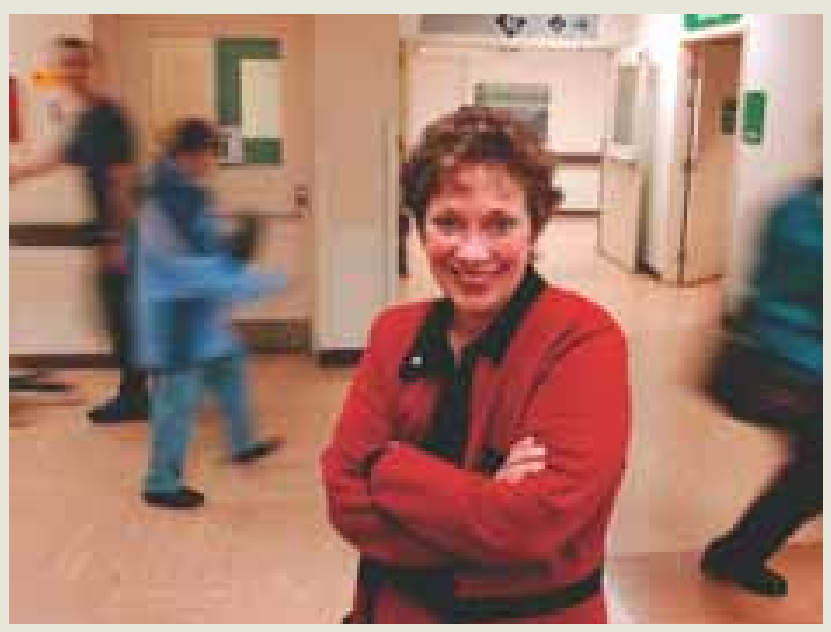

Janet M. Davidson, BScN, MHSA

Janet Davidson is the Chief Operating Officer for Vancouver Acute. Her portfolio includes Vancouver General Hospital (VGH), G. F. Strong Rehabilitation Centre and UBC Hospital. Prior to joining VGH, Janet was the President and CEO Toronto East General Hospital. She has over 25 years of healthcare management experience including her position as the Assistant Deputy Minister of Health for Alberta.

Janet is currently serving her second four-year term as Vice-President (Americas) and Board member of the International Federation of Red Cross and Red Crescent Societies (Geneva). She has received numerous awards including the 125th Anniversary and Queens Jubilee Medals from the Government of Canada.

The most challenging period in my professional career was the time leading up to, and then the decision taken by, the government, to appoint a supervisor and remove the board of my hospital. This was followed by almost a year under provincial supervision until the new board was appointed. As a newly appointed CEO - I had been in place less than six months before things started "heating up" - I was faced with one of a CEO's worst nightmares, an almost complete breakdown in the relationship between governance and management. My role as $\mathrm{CEO}$ was to try and navigate through the multitude of personal, legal and management challenges while maintaining the organization's focus on its primary mandate - "service to patients." Not an easy task, let me tell you!

While the entire time represented a major professional challenge for me, it did present me with a number of key learnings. First, it reinforced for me the fact that maintaining focus is important. I had to continually remind myself that 


\section{Shirlee Sharkey cont'd}

All employees are encouraged to share their ideas, big or small, about work processes and their improvement, new products and services, innovations for staff and clients, new applications of technology and ways to improve communication and connectivity.

My own learning from this experience has been the realization that innovation is about much more than simply a business value proposition. It is a dynamic tool to bring people together, to increase employee engagement, and to ensure the continual development of an organization and its ability to meet the evolving needs of clients in an effective and responsive way.

In a healthcare environment that is somewhat risk-averse and cautious to change, I've learned that it takes a great deal of creativity, energy and optimism to foster a climate of innovation that is necessary to bring profound and needed change.

\section{Janet M. Davidson cont'd}

while the events unfolding were difficult, my job as CEO was to deal with them and to not let them spill over into the day-to-day operations of the hospital. Staff needed to feel reassured that the breakdown in the governance/management relationship and the subsequent appointment of a government supervisor would not impact negatively upon the hospital and the ability of staff to do their work. The face I presented to staff and the public had to be one that demonstrated that I was in control and that operationally at least it was business as usual. The second key learning, and it's related to the first, was reinforcement of the adage "Half the world's troubles never happen." By focusing on what was important and trying not to personalize the situation into a "me/they" issue, I was able to keep the forest in sight - rather than the individual trees. The outcome was a positive one for the hospital, its staff and, its patients. The final key learning for me was never to forget the importance of relationships. When I look back upon that difficult time, while I obviously remember the problems, what comes much more to mind is the people who were there for me during that crisis - the medical staff, my CEO colleagues in other institutions, the members of my executive team and staff throughout the hospital, and the supervisor, to name but a few. Their support and encouragement was invaluable.

Do the lessons I learned from this experience still apply? You bet!

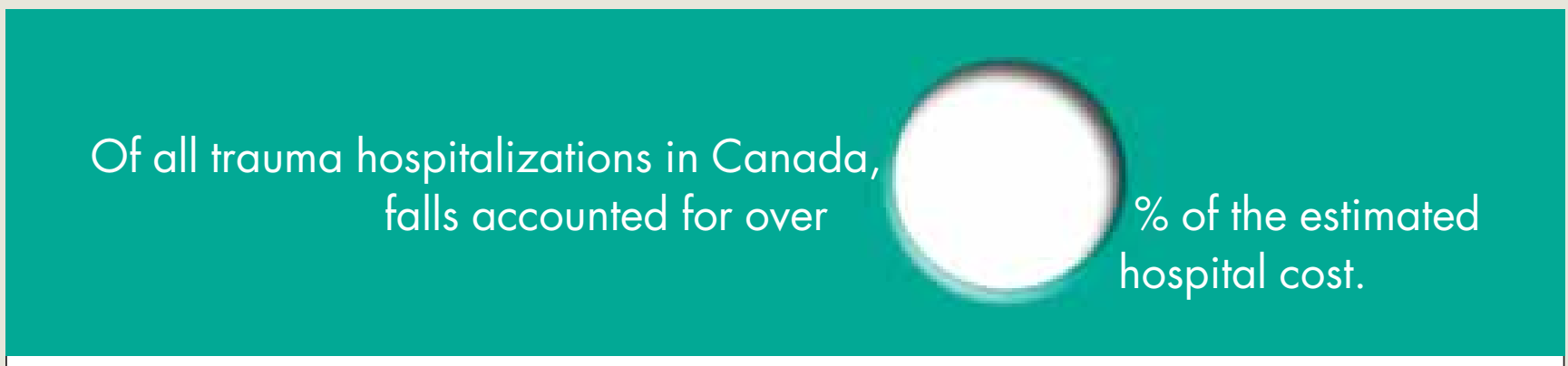

In 2000-01, the estimated total hospital cost for trauma hospitalizations was \$1.5 billion. Falls were the leading cause of trauma admissions, and accounted for over $60 \%$ of this estimate. *

ClHI's National Trauma Registry (NTR) provides national information on trauma hospitalizations, quantifying our understanding of injury in Canada. To learn more, visit us at www.cihi.ca/ntr

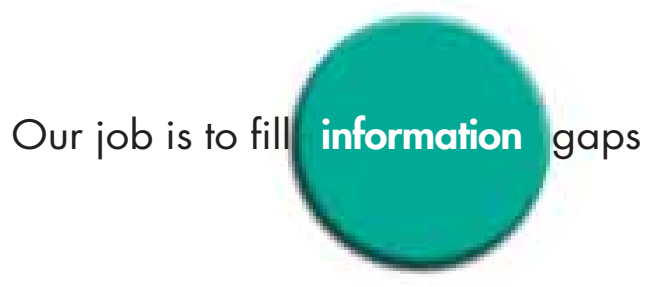

*Based on data from the National Trauma Registry and the Ontario Case Costing Initiative. 


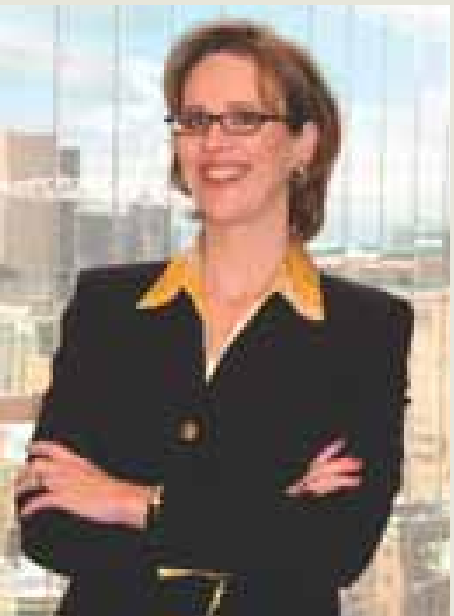

Leslee Thompson,

$\mathrm{BScN}, \mathrm{MScN}, \mathrm{MBA}$

Leslee Thompson is

Provincial Vice-

President, Cancer

System integration and

Performance at Cancer

Care Ontario (CCO), and

Chair of CCO's Provincial

Leadership Council. She

has almost 20 years of

progressive healthcare

leadership experience

that includes senior executive positions in two

provinces leading major restructuring initiatives and mergers.

Her experience has crossed community hospitals, multisite academic centres, a large regional health authority, provincial cancer agencies and government. She also serves as a Director on the Board of Shoppers Drug Mart Corporation.

I joined Cancer Care Ontario in January 2003, with a mandate to drive a province-wide integration process to conclusion by the end of the calendar year. Difficult, yes - but also exciting, challenging and rewarding.

The goal of integration was simple: to improve the quality of care for cancer patients across Ontario. The challenge was to integrate 11 regional cancer centres into their host hospitals, and set the stage for future improvements to the provincial cancer system.

Timelines, teamwork and transparency were three key reasons for success.

Ironically, these were also the factors that made the change process most challenging. When we set deadlines, we stuck to them, even in the midst of SARS, operational pressures and a provincial election. There were many opportunities for this to go off-track but we remained focused, worked efficiently and didn't strive for perfection. Tight timelines helped build momentum and motivation, and forced us to be creative in how we approached our various tasks.

The CEOs collectively steered the process, with support from a few senior people assigned to "get the job done." Hundreds of others were engaged through local and provincial work groups that would start up and stop as required. Decision-making and communication was also streamlined. The type of change required CCO to work closely with the government, keeping them informed and involved along the way. In turn, this led to the government giving us full support and the authority we required to keep moving forward.

Not surprisingly, a number of complications arose along the way. We dealt with these in a timely and transparent fashion, then just kept going. In the end, it was hard work and mutual trust among the key leaders that helped us reach our goals. Now that changes in structure and accountability are complete, $\mathrm{CCO}$ is at the end of a new beginning. Working together, we will now turn our attention to creating the best cancer system in the world.

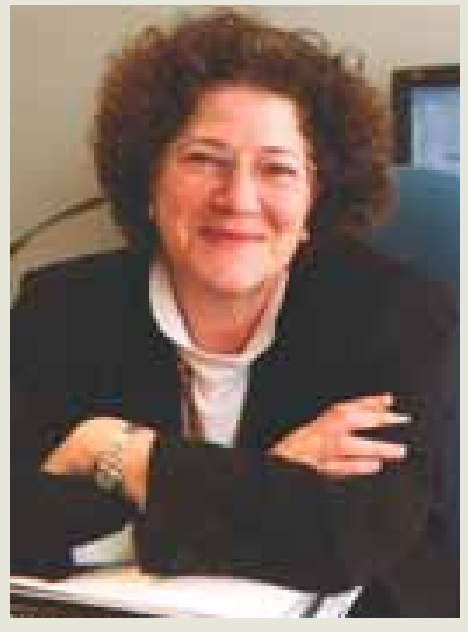

Dora Nicinski, RN, BSN, MSc

Dora Nicinski is the President and CEO of Atlantic Health Sciences Corporation (AHSC). Prior to joining AHSC, Ms. Nicinski was the CEO of the North Okanagan Health Region in Vernon, BC. A registered nurse and career health professional, she has over 16 years of experience as

a hospital administrator and healthcare consultant in British Columbia. She has managed hospitals in several B.C. communities and oversaw the establishment of the province's first regional health authority.

Developing organizational structure within the context of regionalized health services adds a further dimension of complexity to already complex organizations. Geographic areas of responsibility that take days to travel, along with a shift to region-wide program management, provide two disparate arguments for choice of organizational structure.

There is one inclination to ground an organization in region wide program management because of best practice, shared skills and rationalization of resources. There is another inclination to ground an organization in geographic entities because of distinct communities, existing cultural identities and political pressure to retain the independence of the service.

Having worked with three regional health authorities, I have had ample opportunity to test different approaches to regional organizational structures. My conclusion from learning to date is that a matrix organizational structure which is grounded in strategic objectives and values is the best option. That means that organizational structure will evolve as the strengths and objectives of the organization evolve.

In order to succeed, fundamental requirements of successful matrix organizational structure in a program management and regional geographic environment are:

- Clarity of organizational strategic direction

- Demonstration of commitment to stated values

- Competence in leadership

- Clear delineation of areas of responsibility and accountability

- Monitoring of organizational accountability

- Respect for the unique culture of communities

- Effective partnerships with community organizations

- Excellent communication

- Flexibility in reconfiguration as experience teaches 